\title{
Which factors affect willingness-to-pay for automated vehicle services? Evidence from public road deployment in Stockholm, Sweden
}

\author{
Pei Nen Esther Chee ${ }^{1,2^{*}}$ (D) Yusak O. Susilo ${ }^{3,4}$, Yiik Diew Wong ${ }^{1}$ and Anna Pernestål ${ }^{4}$
}

\begin{abstract}
Introduction: Travel demand and travel satisfaction of a transport service are affected by user perceptions of the service quality attributes, and such perceptions should be included in studying user willingness-to-pay (WTP) for automated vehicle (AV) services. This study applied structural equation modelling with service quality attribute perceptions as latent variables affecting WTP.

Objectives: We investigated how WTP AV services are affected by socio-demographic characteristics, knowledge and experiences with $A V$, existing travel modes and particularly, perceptions of the associated service quality attributes. The AV services are: 1) on-demand personalised AV (PAV) service, 2) demand responsive shared AV (SAV) service, and 3) first-/last-mile automated bus (AB) service.

Methods: The data were collected from 584 potential users of a first-/last-mile AB service trial operated in Kista, Stockholm. Results: Results show people hold different expectations towards each type of AV service. These expectations act as the minimum requirements for people to pay for the AV services. Respondents are found to be willing to pay more for PAV service if it is safe, provides good ride comfort, and is competitively priced relative to the price travelling by metro and train over a same distance. Other than service quality attribute perceptions, income level, existing travel modes for daily trips, familiarity with automated driving technology and AB ride experience are important factors affecting WTP for the AV services.

Conclusion: The developed model can be applied to understand expectations of potential users towards a new AV service, and to identify user groups who are willing to pay the senvice. New AV senvices can thus be designed sensibly according to users' actual needs.
\end{abstract}

Keywords: Automated vehicle, Demand responsive, Shared automated vehicle service, Willingness-to-pay model, Market segmentation

\section{Introduction}

Automated vehicle (AV) is a general term to describe the vehicles driven without a human's control, partially or fully. There are several types of automated vehicles (AVs) in the

\footnotetext{
* Correspondence: pnchee@kth.se

${ }^{1}$ School of Civil and Environmental Engineering, Nanyang Technological University, 50 Nanyang Avenue, Singapore 639798, Singapore

${ }^{2} S c h o o l$ of Architecture and Built Environment, Integrated Transport Research Lab, KTH Royal Institute of Technology, SE-100 44 Stockholm, Sweden

Full list of author information is available at the end of the article
}

marketplace including car-like $\mathrm{AV}$, van-like $\mathrm{AV}$ and bus-like AV. They are categorised based on their capacity. Bus-like AV with a higher passenger capacity tends to be more economical [22] and provides sustainable [12] travel option in urban areas. Based on the insights from existing AV ecosystem, three types of AV business models are likely to happen: 1) on-demand personalised $A V(P A V)$ service, 2) demand responsive shared $A V(S A V)$ service, and 3) first-/last-mile

\section{Springer Open}

(๑) The Author(s). 2020 Open Access This article is licensed under a Creative Commons Attribution 4.0 International License, which permits use, sharing, adaptation, distribution and reproduction in any medium or format, as long as you give appropriate credit to the original author(s) and the source, provide a link to the Creative Commons licence, and indicate if changes were made. The images or other third party material in this article are included in the article's Creative Commons licence, unless indicated otherwise in a credit line to the material. If material is not included in the article's Creative Commons licence and your intended use is not permitted by statutory regulation or exceeds the permitted use, you will need to obtain permission directly from the copyright holder. To view a copy of this licence, visit http://creativecommons.org/licenses/by/4.0/. 
automated bus $(A B)$ service. Unlike SAV, passengers who choose PAV do not share the ride with other passengers.

Willingness-to-pay (WTP) was often explored in AV/ AV service acceptance studies. For example, CityMobil2 project [20] which implemented shared automated shuttles in six cities of La Rochelle, Trikala, Lausanne, Oristano, Vantaa, and San Sebastian assessed user acceptance of first -/last mile feeder service using two indicators: willingnessto-use (WTU) and WTP. WTP is defined as the highest price an individual is willing to pay for a product or service [9]. Adoption rate of an AV service is sensitive to both the service price and people's WTP for the service. Results from the simulation of the long term (2015 to 2045) adoption rate of connected automated vehicle (CAV) technologies for a light duty vehicle fleet in the U.S. by Bansal and Kockelman [5] showed it is unlikely for the technologies to reach $50 \%$ penetration rate by the year 2045 without increase of people's WTP for AV technologies. Similar to other products/services, the demand of an AV/AV service is sensitive to user WTP. It is determined by the aggregation of WTP values across the users. The adoption rate of CAV which is a type of AV is affected by WTP and user satisfaction with their purchases [28].

There have been a substantial number of studies investigating WTP for AV and the technology including [2, 4, $7,10,14,17,19,28]$. User perceptions, which are crucial towards a successful deployment of a product/service delivery, were not investigated in the past studies except in [2]. When AVs are used to run different services, investigating the impacts of user perceptions of key service attributes on WTP of the AV services are as important as the impacts on WTU the service. Herein, WTP estimates are useful when planning for AV service demands. Operational and service quality attributes, such as service frequency, length of trip time, and service provider's responsiveness in public transport services, play a more crucial role in influencing the travel demand and travel satisfaction than the physical design and technology of the vehicle itself [1]. Therefore, user expectation, perceptions, and acceptance towards such operational characteristics should not be disregarded when investigating factors that influence user WTP for AV services.

This study applied structural equation modelling with service quality attribute perceptions as latent variables to investigate significant factors affecting WTP. In essence, we investigated how WTP AV services are affected by sociodemographic characteristics, knowledge and experiences with $\mathrm{AV}$, existing travel modes and particularly, perceptions of the associated service quality attributes. The AV services are: 1 ) on-demand personalised AV (PAV) service, 2) demand responsive shared $A V(S A V)$ service, and 3) first-llast-mile automated bus $(A B)$ service. The data analysed in this study were collected from 584 potential users of a first-/last-mile AB service trial operated in Kista, Stockholm from January to June
2018. The potential users lived, worked and studied in or around the operation site of the $\mathrm{AB}$ service.

In Section 2, existing literature investigating WTP for $\mathrm{AV}$ or AV technology is reviewed, and research gaps are identified and highlighted. Also, variable selection and the proposed structural equation model are explained. Then, Section 3 describes the case study and the associated data, followed by Section 4 that covers results and discussions. The paper ends with the conclusions in Section 5.

\section{Literature review}

This section reviews past literature investigating WTP for AV or AV technology, and states the research gaps to be addressed. Then, it is followed by variable selection and formulation of the model being tested.

\subsection{Past studies investigating WTP for AV/AV technology}

WTP is defined as the highest price an individual is willing to pay for a product or service. Pricing for a service can be operationalised in two ways: cost-based pricing and valuebased pricing. Cost-based pricing is a pricing method that sets a selling price of goods or services by adding a fixed sum or a percentage of the total cost as profit to the cost of the product. Value-based pricing prices goods or services according to their perceived value to customers. When valuebased pricing is used, the perceived values which influence one's WTP for a service must be identified [15]. In the case of operating an AV service, the expected service quality attributes influence one's WTP for the service. Furthermore, perceptions vary according to social-demographics and familiarity with the content and context of a service [29]. Considering valid estimates of WTP for the type of AV service with inclusion of the relevant perceptions are indeed vital for sensible pricing strategy of the AV service [3].

Asgari and Jin [2], Liu et al. [19], Bansal and Daziano [4], Talebian and Mishra [28], Jiang et al. [14], Daziano et al. [10], Bansal et al. [7], and Kyriakidis et al. [17] investigated WTP for AV or AV technology. Jiang et al. [14], Bansal et al. [7], and Kyriakidis et al. [17] examined WTP itself only, without investigating the factors affecting WTP. On the other hand, several studies looked into the factors influencing WTP for AV or AV technology. Daziano et al. [10] used mixed logit models to estimate WTP for private AV with different levels of automation for various sociodemographics. The results showed that the preferences for automation are diverse. Households who are not aware of driverless car technology are not willing to pay extra money for the technology. Out of the 1260 respondents with good representation of U.S. population, those who drive long distance, being aware of driverless car technology, own car, and with higher education have the most desire towards the technology and are willing to pay USD2,784 for a privately owned automated car with partial automation (level-3 and 
level-4 automation) and USD6,580 for a privately owned automated car with full automation.

Talebian and Mishra [28] included WTP in the simulation model of the adoption of CAV and found that WTP is affected by peer-to-peer communication about the technology. Bansal and Kockelman [6] regressed sociodemographic predictors, location-based predictors, travelbased predictors, tech-based predictors and safety-based predictors with WTP for private AV with different automation levels, and found that older people and experienced drivers have lower WTP for the technologies. Liu et al. [19] tested a psychological model to explain WTP for fully automated driving technology; social trust is identified to impact WTP directly rather than through perceived risk and perceived benefit.

Lastly, other than including socio-demographic variables like in the afore-mentioned studies, [2] included respondent attitudes towards driving, factors affecting mode choice selection, shared transportation, multitasking and new technology in the structural equation model to study their effects on WTP for four levels of automation (basic vehicles, adding advanced features, partial automation and full automation). They concluded people are willing to pay more when they believe that using the automated features/services will provide them with better utility in terms of time and cost savings, stress reduction, convenience and quality of life. This highlights the importance of understanding WTP from user perceptions point of view, particularly their level of expectation or satisfaction with the service quality attributes of an AV service.

The understanding of user expectation, perceptions and satisfaction about a product or service attributes/ characteristics is crucial towards deploying a successful product and/or service delivery [18, 21]. Such knowledge is important to operators and stakeholders who are keen to provide market-driven AV services, and fosters more realistic estimation of the long-term demands and impacts from their implementations. As highlighted by Abenoza et al. [1] operational and service quality attributes especially service frequency, length of trip time, and service provider's responsiveness in public transport services, play a more crucial role in influencing the travel demand and travel satisfaction than the physical design and technology of the vehicle itself. Herein, user expectation, perceptions, and acceptance towards such operational characteristics should not be disregarded when investigating factors that influence user WTP for AV services. Moreover, the results from Shin et al. [27] who evaluated WTP of South Koreans for private vehicles with different smart options (automated driving, connectivity, voice command, wireless internet and availability of software application) at different option prices showed that consumers are homogenously sensitive to price but vary in their preferences of the smart options. This shows the importance to understand the effects of the associated perceptions of the AV services at individual service quality attributes instead of the services as a whole bundle.

WTP values for various AV services in past studies except [2] explored mainly the effects of sociodemographic characteristics, commuting behaviours and other non-attitudinal variables on WTP for AV or AV technology. There is hardly any study that determines the impacts of service quality attributes of AV deployment towards one's WTP for these services. Also, knowledge is still very sparse about WTP for SAV services, particularly factors associated with user WTP for SAV service as compared to PAV service. To fill these gaps, this study focuses on identifying significant explanatory factors of WTP for three types of AV services: 1) on-demand personalised AV (PAV) service, 2) demand responsive shared $A V$ (SAV) service, and 3) first-/last-mile automated bus (AB) service that operates in the same way as existing scheduled public bus service, particularly the effects of perceived service quality attributes on WTP for each type of service. Factors that drive or hinder WTP for the services can be for: 1) WTP to try out a new service, with no intention to use it habitually, and 2) WTP to pay for a service, with intention to use it regularly. This study focuses on the later, with target on regular usage.

\subsection{Variable selection and model formation}

This study aims to investigate the core service quality attribute expectations affecting WTP for three types of AV services: PAV, SAV and AB services, and also how these perceptions vary with respect to sociodemographic characteristics, knowledge and experiences with $\mathrm{AV}$, and existing travel modes. Herein, structural equation modelling with service quality attribute perceptions as latent variables is applied to achieve the objective.

Socio-demographic predictors which are significant to WTP for AVs such as age [7], gender and income level $[7,17]$ are included in the model. Additionally, significant factors influencing acceptance of AVs such as technology awareness [26], use of multiple travel modes [16], and ride experience [7] are also included. Salonen [24], Eden et al. [11], Scheltes and de Almeida Correia [25] and Piao et al. [23] investigated acceptance of using small AB. On-board safety [23, 24], comfort [11], travel time [7, 25], travel fare $[7,23]$ and presence of steward [23] are found to be influential to people's acceptance of $\mathrm{AB}$ usage. Hence, service quality attributes including frequency, safety, ride comfort, travel time and travel cost are included as latent variables in the structural equation model applied in this study. Figure 1 shows the 


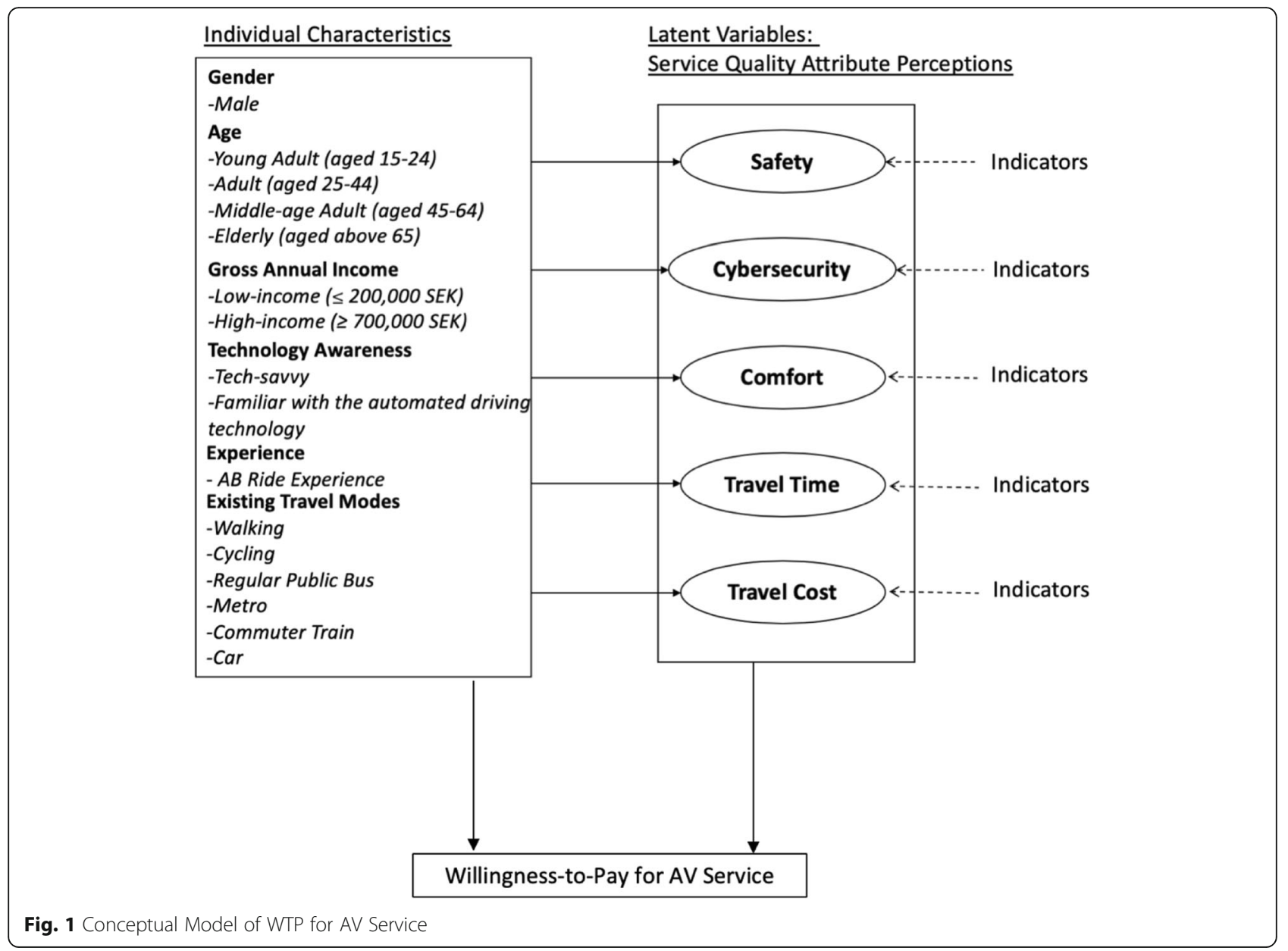

constructed structural equation model with service quality attribute perceptions as latent variables. The model is built using the framework of the structural modelling equation part of the Integrated Choice and Latent Variable (ICLV) model [8]. However, the whole ICLV model is not adopted because there is no choice selection involved in this study. This means that, for this study, WTP is not inferred from a stated preference study in which respondents state their preferences through their choices. Instead, the respondents directly state the amount of money they are willing to pay for the AV services.

\section{Methodology}

The data were collected during the 6-month (January to June 2018) trial operation of a first-/last-mile automated bus (AB) service in Kista, Stockholm. This section starts with a brief description of the trial operation, followed by a description of the data and the method to analyse the data.

\subsection{Case study}

A free first-/last-mile $A B$ service was operated from January to June 2018 in Kistagången along the route shown in Fig. 2 in Kista, Stockholm. The automated buses used in the trial operation were 10-passenger EZ10 automated buses as shown in Fig. 3. Three rounds of panel surveys were conducted and administrated by a Swedish survey company recruited by the KTH research group. The respondents were recruited by the survey company to take part in three rounds of surveys throughout the period from February 2018 to June 2018. The data analysed in this study are those data collected in the first round of the surveys. Participants who completed all three rounds of surveys were entitled to participate in the contest to win one of ten cash prizes of 1500 Swedish kronor (about 142 euro or 158 USD).

The survey targeted potential users of the service, primarily those who lived, worked or studied in the area. The area is a science and technology park which hosts many prominent technology companies and a 


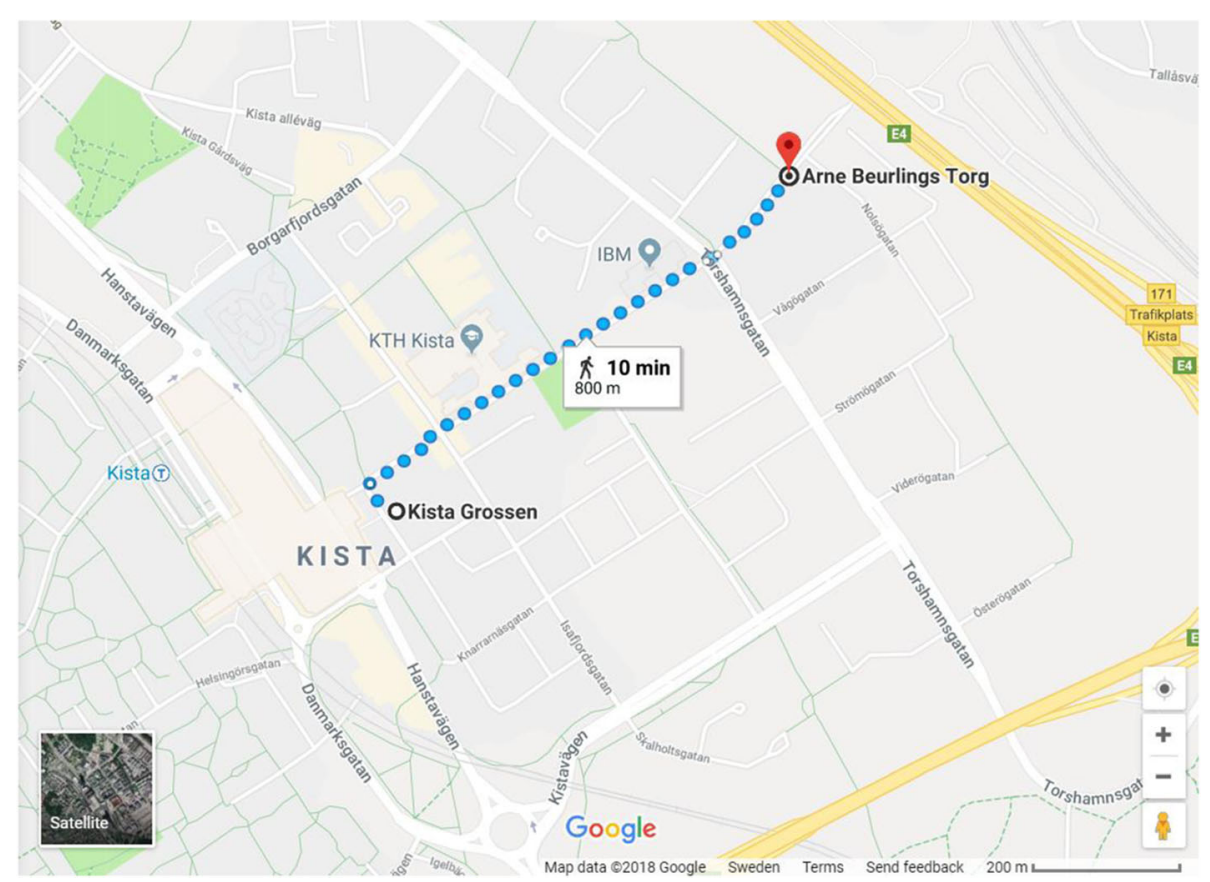

Fig. 2 Route in which EZ10 operated during the trial operation period (map from Google Maps [13])

technological university. Unlike previous studies in which respondents were randomly selected, this survey focused on potential users of the trial-operated first -/last-mile AB service. Data were collected from 604 respondents of whom 584 had complete data which were analysed.

\subsection{Survey and data description}

\subsubsection{There are three parts in the survey}

The first part asked for:

1) basic details including gender, age, gross annual income before tax

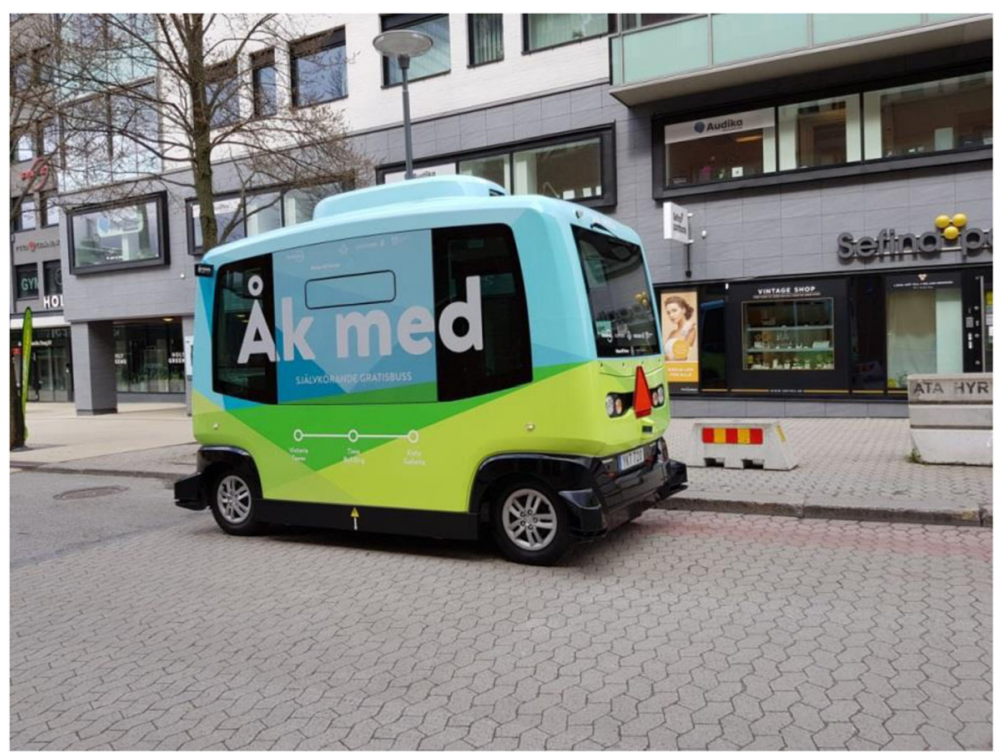

Fig. 3 Picture featuring EZ10, the small automated vehicle used in the trial operation in Kista, Stockholm [photo taken on 4th May 2018 by SARA1 research team] 
2) tech-savviness (defined as being well informed about or know how to use computers, mobile phones and electronic devices)

3) level of familiarity with automated driving technology

4) existing travel modes for daily commute

Table 1 shows the distribution of socio-demographic characteristics of the sample of 584 respondents. There are more male respondents $(64.6 \%)$ in the survey. Also, most of the respondents (46.1\%) are between 45 to 64 years old, working (58.9\%), have at least an undergraduate degree $(78.6 \%)$ and being tech-savvy (93.8\%). Nearly two-thirds (57\%) of the respondents claimed to be familiar with the technologies used to enable automated road vehicle to drive without human driver. Close to half $(46.7 \%)$ of the respondents had taken at least one automated bus ride.

The second part asked for respondent's perception of:

(1) safety travelling by AV, with 3 questions

(2) cybersecurity, with 2 questions

(3) AV ride comfort, with 3 questions

(4) travel time, with 4 questions

(5) travel fare, with 3 questions

Each service attribute quality perception is a latent variable. Table 2 shows the list of indicators of each service attribute quality perception. In general, the respondents had positive perceptions with the safety, ride comfort and travel fare of an automated bus service. However, they had negative perceptions towards cybersecurity and travel time of an automated bus service. Table 4 in Appendix 1 shows the pattern matrix of the items from factor analysis. The results show that the items have good fit with the respective latent variable. Also, there is no significant correlation between each pair of the latent variables, as shown in Table 5 in Appendix 1.

The third part asked for:

Willingness-to-pay (WTP) for the three types of $A V$ services as if to use the service for a long period of time (WTP is measured as the amount of money one is willing to pay on top of the public transport monthly pass one was paying at the time of survey).

\subsection{Structural equation modelling}

Structural equation modelling (SEM) which is also called analysis of covariance structures or causal modelling was applied in this study. A structural equation model with latent variables comprises two parts: 1 . structural model, and 2. measurement model. The structural model contains the equations for predicting the values of endogenous variables. It has the form of:
Table 1 Distribution of socio-demographic characteristics of the respondents $(n=584)$

\begin{tabular}{|c|c|}
\hline Characteristics/sample group & Total $(n=584), \%$ \\
\hline \multicolumn{2}{|l|}{ Gender } \\
\hline Male & 64.6 \\
\hline Female & 33.4 \\
\hline \multicolumn{2}{|l|}{ Age } \\
\hline Children (aged under 15 years) & 0 \\
\hline Young Adult (aged 15-24) & 20.7 \\
\hline Adult (aged 25-44) & 27.7 \\
\hline Middle-age Adult (aged 45-64) & 46.1 \\
\hline Elderly (aged above 65) & 5.1 \\
\hline \multicolumn{2}{|l|}{ Employment Status } \\
\hline Working & 58.9 \\
\hline Business Owner & 3.3 \\
\hline At School & 31 \\
\hline Permanently Retired from Work & 4.1 \\
\hline \multicolumn{2}{|l|}{ Education Background } \\
\hline Undergraduate or above & 78.6 \\
\hline \multicolumn{2}{|l|}{ Gross Annual Income (before tax) in Swedish Kronor (SEK) } \\
\hline $\begin{array}{l}\text { Low-income }(\leq 200,000 \text { SEK } \cong 19,127 \text { euro / 21,386 } \\
\text { USD) }\end{array}$ & 16.6 \\
\hline $\begin{array}{l}\text { High-income }(\geq 700,000 \text { SEK } \cong 66,943 / 74,851 \\
\text { USD) }\end{array}$ & 41.1 \\
\hline \multicolumn{2}{|l|}{ Technology Awareness } \\
\hline $\begin{array}{l}\text { Tech-savvy: well informed about or know how } \\
\text { to use computers, mobile phones and electronic } \\
\text { devices. }\end{array}$ & 93.8 \\
\hline $\begin{array}{l}\text { Familiar with the technologies used to enable } \\
\text { automated road vehicle to drive without human } \\
\text { driver }\end{array}$ & 57 \\
\hline \multicolumn{2}{|l|}{ Existing Travel Modes } \\
\hline Walking & 26.5 \\
\hline Cycling & 13.5 \\
\hline Regular Public Bus & 39.6 \\
\hline Metro & 48.3 \\
\hline Commuter Train & 26.5 \\
\hline Car & 26.2 \\
\hline Private Shuttle Service & 0 \\
\hline \multicolumn{2}{|l|}{ Automated Bus Ride Experience } \\
\hline Never & 53.3 \\
\hline At least once & 46.7 \\
\hline
\end{tabular}

$$
y=A y+B x+e
$$

where

$A=$ matrix $(p \times p)$ of direct effects between pairs of the $\mathrm{p}$ endogenous variables, $B=$ matrix $(p \times q)$ of regression effects of the $q$ endogenous variables, 
Table 2 Items/indicators for service attribute perception

\begin{tabular}{|c|c|c|c|c|}
\hline Service Attribute Perception & Item/Indicator & Question & Mode & Mean \\
\hline \multirow[t]{3}{*}{ Safety } & SafetyWithoutSteward & $\begin{array}{l}\text { I feel } \\
\text { automated vehicle. ( } 1 \text { if Extremely Unsafe; } 2 \text { if Unsafe; } 3 \\
\text { if Neutral; } 4 \text { if Safe; } 5 \text { if Extremely Safe) }\end{array}$ & 4 & 3.2 \\
\hline & Safety_Pedestrian & $\begin{array}{l}\text { From the point of view of a pedestrian who wants to } \\
\text { cross a road without using pedestrian crossing facilities, } \\
\text { I feel } \\
\text { vehicle on public road. ( } 1 \text { if Extremely Unsafe; } 2 \text { if } \\
\text { Unsafe; } 3 \text { if Neutral; } 4 \text { if Safe; } 5 \text { if Extremely Safe) }\end{array}$ & 4 & 3.2 \\
\hline & Safety_CarDriver & $\begin{array}{l}\text { From the point of view of a non-automated car driver, I } \\
\text { feel } \quad \text { when I encounter an automated vehicle } \\
\text { on public road. ( } 1 \text { if Extremely Unsafe; } 2 \text { if Unsafe; } 3 \text { if } \\
\text { Neutral; } 4 \text { if Safe; } 5 \text { if Extremely Safe) }\end{array}$ & 4 & 3.2 \\
\hline \multirow[t]{2}{*}{ Cybersecurity } & Cybersecurity_Hacked & $\begin{array}{l}\text { I feel that the chance of its automated driving system } \\
\text { being hacked would be: ( } 1 \text { if Extremely Low; } 2 \text { if Low; } 3 \\
\text { if Neutral; } 4 \text { if High; } 5 \text { if Extremely High) }\end{array}$ & 2 & 2.9 \\
\hline & Cybersecurity_GPS & $\begin{array}{l}\text { I feel that the chance of its GPS data being shared with } \\
\text { unauthorised parties would be: ( } 1 \text { if Extremely Low; } 2 \text { if } \\
\text { Low; } 3 \text { if Neutral; } 4 \text { if High; } 5 \text { if Extremely High) }\end{array}$ & 3 & 2.9 \\
\hline \multirow[t]{3}{*}{ Ride Comfort } & RideComfort_Tech & $\begin{array}{l}\text { I feel that the level of on-board comfort due to driving } \\
\text { speed and driving patterns of the automated vehicle } \\
\text { would be: ( } 1 \text { if Extremely Uncomfortable; } 2 \text { if } \\
\text { Uncomfortable; } 3 \text { if Neutral; } 4 \text { if Comfortable; } 5 \text { if } \\
\text { Extremely Comfortable) }\end{array}$ & 3 & 3.4 \\
\hline & RideComfort_Facilities & $\begin{array}{l}\text { I feel that the level of on-board comfort due to the } \\
\text { facilities inside the automated vehicle would be: ( } 1 \text { if } \\
\text { Extremely Uncomfortable; } 2 \text { if Uncomfortable; } 3 \text { if } \\
\text { Neutral; } 4 \text { if Comfortable; } 5 \text { if Extremely Comfortable) }\end{array}$ & 3 & 3.3 \\
\hline & OverallRideComfort & $\begin{array}{l}\text { I feel that an automated vehicle ride would be: ( } 1 \text { if } \\
\text { Extremely Unpleasant Ride; } 2 \text { if Unpleasant Ride; } 3 \text { if } \\
\text { Neutral; } 4 \text { if Pleasant Ride; } 5 \text { if Extremely Pleasant Ride) }\end{array}$ & 3 & 3.2 \\
\hline \multirow[t]{4}{*}{ Travel Time } & Time_RegularPublicBus & $\begin{array}{l}\text { Perception about travel time by automated vehicle in } \\
\text { comparison to travel time by regular public bus given } \\
\text { same distance and route ( } 1 \text { if Much Longer than by } \\
\text { regular public bus; } 2 \text { if Longer than by regular public } \\
\text { bus; } 3 \text { if Same; } 4 \text { if Shorter than by regular public bus; } 5 \\
\text { if Much Shorter than by regular public bus) }\end{array}$ & 3 & 2.7 \\
\hline & Time_Metro & $\begin{array}{l}\text { Perception about travel time by automated vehicle in } \\
\text { comparison to travel time by metro given same } \\
\text { distance and route ( } 1 \text { if Much Longer than by metro; } 2 \\
\text { if Longer than by metro; } 3 \text { if Same; } 4 \text { if Shorter than by } \\
\text { metro; } 5 \text { if Much Shorter than by metro) }\end{array}$ & 2 & 2.3 \\
\hline & Time_Train & $\begin{array}{l}\text { Perception about travel time by automated vehicle in } \\
\text { comparison to travel time by train given same distance } \\
\text { and route ( } 1 \text { if Much Longer than by train; } 2 \text { if Longer } \\
\text { than by train; } 3 \text { if Same; } 4 \text { if Shorter than by train; } 5 \text { if } \\
\text { Much Shorter than by train) }\end{array}$ & 2 & 2.3 \\
\hline & Time_Car & $\begin{array}{l}\text { Perception about travel time by automated vehicle in } \\
\text { comparison to travel time by car given same distance } \\
\text { and route ( } 1 \text { if Much Longer than by car; } 2 \text { if Longer } \\
\text { than by car; } 3 \text { if Same; } 4 \text { if Shorter than by car; } 5 \text { if } \\
\text { Much Shorter than by car) }\end{array}$ & 2 & 2.2 \\
\hline \multirow[t]{2}{*}{ Travel Fare } & Fare_RegularPublicBus & $\begin{array}{l}\text { Perception about travel fare by automated vehicle in } \\
\text { comparison to travel fare by regular public bus given } \\
\text { same distance and route ( } 1 \text { if Much More Expensive } \\
\text { than by regular public bus; } 2 \text { if More Expensive than by } \\
\text { regular public bus; } 3 \text { if Same; } 4 \text { if Cheaper than by } \\
\text { regular public bus; } 5 \text { if Much Cheaper than by regular } \\
\text { public bus) }\end{array}$ & 3 & 3.4 \\
\hline & Fare_Metro & Perception about travel fare by automated vehicle in & 3 & 3.3 \\
\hline
\end{tabular}


Table 2 Items/indicators for service attribute perception (Continued)

\begin{tabular}{|c|c|c|c|c|}
\hline Service Attribute Perception & Item/Indicator & Question & Mode & Mean \\
\hline & & $\begin{array}{l}\text { comparison to travel fare by metro given same } \\
\text { distance and route ( } 1 \text { if Much More Expensive than by } \\
\text { metro; } 2 \text { if More Expensive than by metro; } 3 \text { if Same; } 4 \\
\text { if Cheaper than by metro; } 5 \text { if Much Cheaper than by } \\
\text { metro) }\end{array}$ & & \\
\hline & Fare_Train & $\begin{array}{l}\text { Perception about travel fare by automated vehicle in } \\
\text { comparison to travel fare by taking train given same } \\
\text { distance and route ( } 1 \text { if Much More Expensive than by } \\
\text { taking train; } 2 \text { if More Expensive than by taking train; } 3 \\
\text { if Same; } 4 \text { if Cheaper than by taking train; } 5 \text { if Much } \\
\text { Cheaper than by taking train) }\end{array}$ & 4 & 3.4 \\
\hline
\end{tabular}

$y=$ column vector of $p$ endogenous variables, $x=$ column vector of q exogenous variables,

$e=$ column vector of the error terms.

The measurement model indicates how the latent variables are related to the observed variables.

The structural equation model (SEM) as shown in Fig. 1 with the indicators listed in Table 2 was analysed using SPSS AMOS. SEM is chosen because it allows estimation of multiple correlated decisions simultaneously, and inclusion of latent variables. Before performing SEM analysis, three assumptions are to be checked. First, the residuals of the regression must be normally distributed. This assumption can be checked by assessing histogram or normal $\mathrm{p}-\mathrm{p}$ plot of the residuals of the regression. Secondly, there must not be multi-collinearity in the data. This can be checked by assessing Pearson's bivariate correlation matrix, making sure that the correlation coefficients among all independent variables be less than 0.8. Lastly, the data should be homoscedastic, which can be ascertained by assessing the scatter plot of residuals versus predicted values. These assumptions were duly checked, as presented in Appendix 2.

\section{Results and discussions}

4.1 Distribution of willingness-to-pay for AV services

Figure 4 shows the distribution of the WTP for: 1) ondemand personalised AV (PAV) service, 2) demand responsive shared AV (SAV) service, and 3) first-/last-mile automated bus (AB) service. Almost half of the respondents $(44 \%)$ were not willing to pay additional fee for $A B$ service on top of their monthly travel pass. The distribution of WTP for PAV service is more evenly distributed

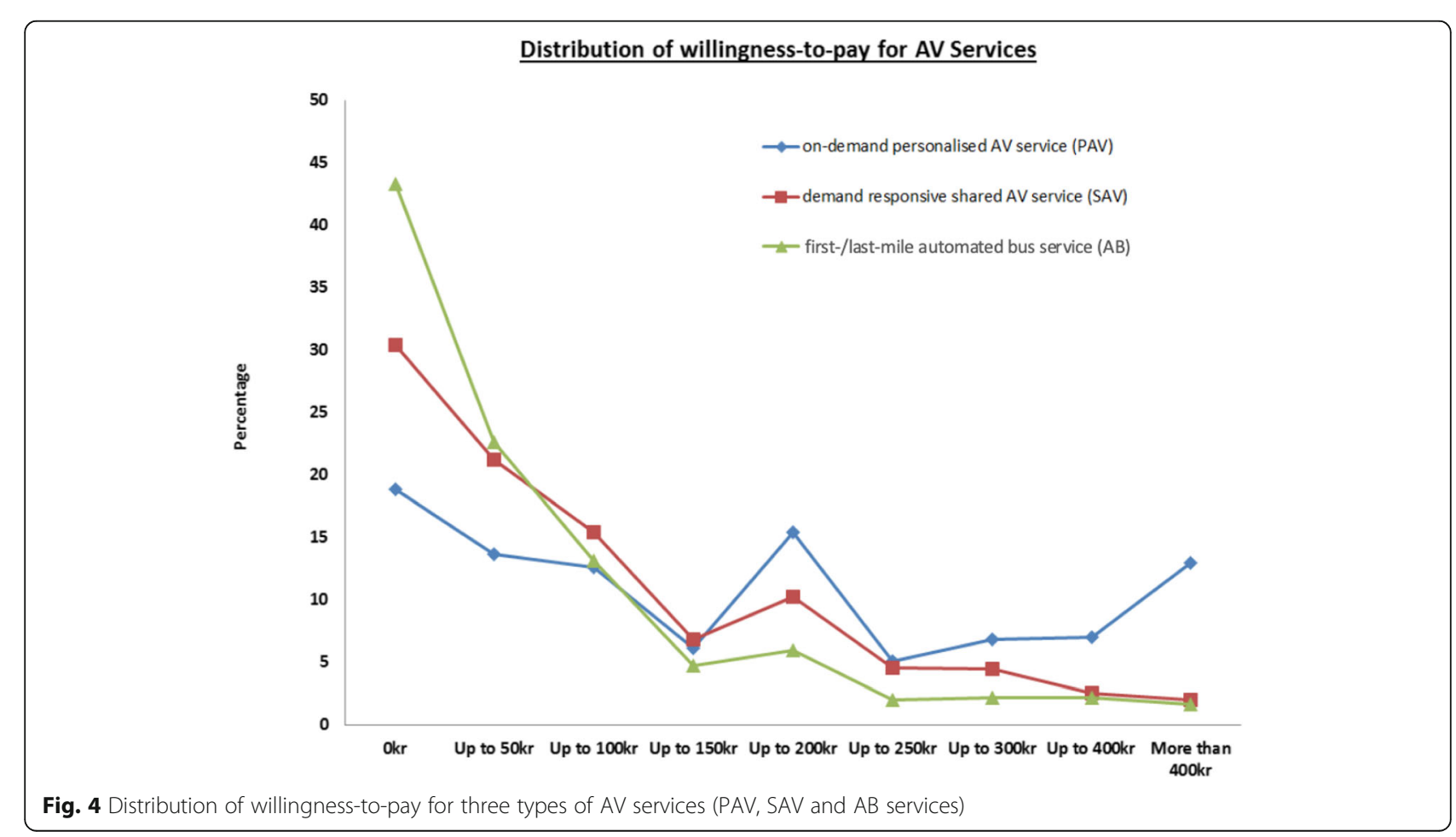


Table 3 Model fit measures of the tested model

\begin{tabular}{lcccc}
\hline & CMIN/df & RMSEA & SRMR & GFI \\
\hline Model fit indicator & 2.780 & 0.055 & 0.073 & 0.924 \\
\hline
\end{tabular}

than others. About $16 \%$ of the respondents were willing to pay up to 200 Kronor (about 19 euro or USD 21) to gain access to PAV service given the same travel distance. Surprisingly, there were about $12 \%$ of the respondents willing to pay more than 400 Kronor (about 38 euro or USD 42) on top of their monthly travel pass to access the service.

\subsection{Model fit}

Model fit of the model adopted in this study, as shown in Fig. 1, is examined. CMIN/df, Root Mean Square Error of Approximation (RMSEA), Standardised Root Mean Square Residual (SRMR), and Goodness of Fit (GFI), are used to examine the model fit of the proposed model. CMIN/df value between 2 to 5 indicates a reasonable fit. RMSEA value which is equal to or less than 0.08 indicates an acceptable error of approximation. SRMR is the square root of the difference between the hypothesised model and the residuals of the sample covariance matrix. A SRMR value which is less than 0.08 indicates good fit. GFI value close to 1 indicates a perfect fit and GFI value more than 0.90 indicates a good model fit. Table 3 shows the model fit measures of the model. This model has good fit because all the requirements for the indicators are fulfilled.

\subsection{Significant factors influencing WTP for PAV, SAV and $A B$ services}

Figure 5 shows the significant factors influencing WTP for respective PAV, SAV, AB services. Values with one decimal place are the regression effects of the service quality attribute variables and individual characteristic variables on WTP for the services. Also, the path coefficients leading from the latent exogenous variables to the indicators are presented, with the coefficients shown by values with two decimal places.

The results show that respondents held different expectations on the AV services. The expected service quality attributes can be treated as the minimum requirements for the respondents to pay for the AV services willingly. Consumers expect PAV service to be safe, with satisfactory ride comfort and be priced competitively; SAV service to be safe and with good ride comfort; $A B$ service to be safe and with acceptable travel time in comparison to travelling by metro, train and car. People would be less willing to pay for the services when the minimum requirements cannot be fulfilled.

Income level, existing travel modes for daily trips, familiarity with automated driving technology and $A B$ ride experience are significant predictors of WTP for the AV services. Respondents who use car for daily trips and existing public bus users are more willing to pay more for on-demand PAV service. Also, similar to the finding by Asgari and Jin [2], those who have taken at least one $\mathrm{AB}$ shared ride have greater WTP for PAV service. On the other hand, those who know well about automated driving technology are less willing to pay for PAV service. This observation is contrary with the finding by Daziano et al. [10] who found that people who know more about automated driving technology have higher WTP for private AV with full level of automation. This contrary finding signals respondents' distrust of the ability of AV services to operate safely, as demonstrated in the respective result presented in Fig. 6. High income holders are less willing to pay for demand responsive SAV service. There is one highlight in the results: people who travel by commuter train for daily trips have less willingness to pay for any of the AV services. This may be associated to the context of this study in which the trial-operated AV service was not connected to the train station in the area.

Figure 6 shows the factors contributing to respondents' perceived safety, ride comfort and fare

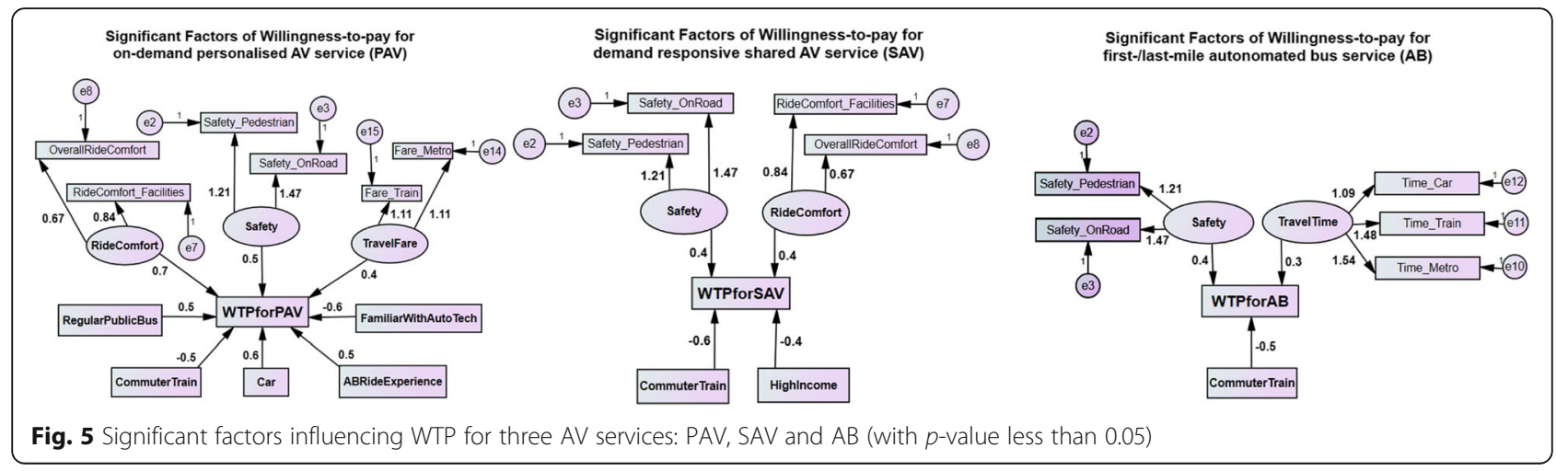




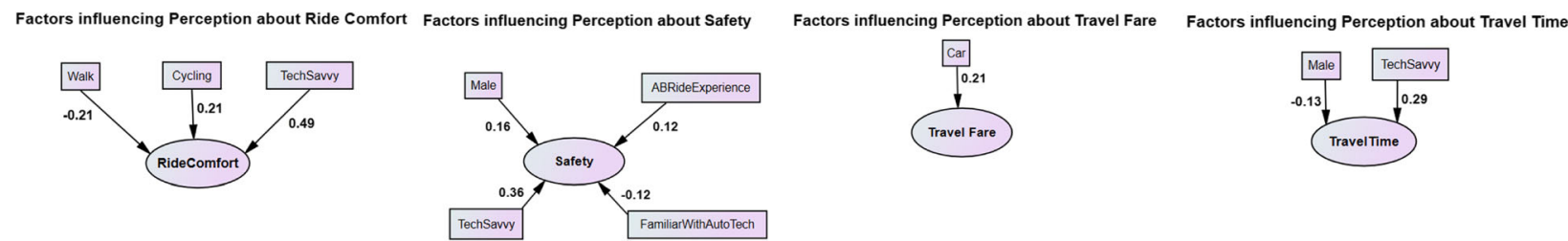

Fig. 6 Significant factors influencing service quality attribute perception (with p-value less than 0.05)

affordability in using an AV service. The values are the regression effects of the individual characteristic variables on the service quality perceptions. The results provide a quick glance into the perceptions of different user groups. Respondents who are tech-savvy perceive AV ride to be comfortable, safe and with acceptable travel time in comparison to travelling by metro, train and car. Also, those who ride bicycle for daily trip find that using AV service is comfortable. Male respondents are more confident with the safety of AV. Car users perceive AV services to be a more affordable travel option than driving a car.

On the other hand, respondents who walk for daily trips perceive AV ride to be less comfortable. People who know well about automated driving technology are more sceptical with the safety of using an AV service.

\section{Conclusion}

AV services are services operated using new innovation by way of automated driving technology. Hence, cognitive responses which have long been included in acceptance studies of a service or a new innovation should not be ignored in the analysis of willingness to pay (WTP) for AV services. The results show that cognitive responses such as service quality perceptions are significant to people's WTP for AV services. Moreover, the perceptions vary according to socio-demographics, travel characteristics, level of experience and familiarity with the technology or automated vehicle as demonstrated in this study. The model is able to further advance the AV WTP model with attitudinal factors [2] through its ability to explain the impacts of individual characteristics on the perceptions.

In conclusion, service quality attribute perceptions play an important role in people's WTP for AV services. People hold different expectations towards each type of AV service. These expectations act as the minimum requirements for people to pay for the AV services. In essence, respondents are willing to pay more for PAV service if the service is safe, provides good ride comfort and offers competitive price in comparison to the price travelling by metro and train given the same distance. Other than service quality attribute perceptions, income level, existing travel modes for daily trips, familiarity with automated driving technology and $\mathrm{AB}$ ride experience are important factors affecting WTP for the AV services. These align with past findings by Bansal et al. [7] in which age and income level were found to be significant factors affecting WTP for AV.

If PAV service is priced competitively in comparison to the price travelling by metro and train given the same distance, existing car owners would switch from driving to using the service. Currently, people who have taken $\mathrm{AB}$ ride trial-operated in Kista, Stockholm perceive using an AV service to be safe and comfortable. There are two user groups which require special attentions. They are people who walk for daily trips and people who know well about automated driving technology. People who choose to walk for daily trips perceive the ride comfort in using an AV service to be bad. People who understand well about automated driving technology are sceptical about the safety of using an AV service. The proposed model is useful to the operators who are keen in introducing new AV services. It can be applied to understand the expectations of potential users towards a new AV service, and to identify user groups which are willing to pay the service so that the new AV service is designed sensibly according to users' actual needs.

The findings obtained are based on the responses collected from people who lived in or around Kista Science City and Helenelund train station which is a science and technology park with many prominent technology companies and a technological university. The socio-demographics of the respondents were skewed more towards the tech-savvy and being highly educated. This contributes to limitation of the findings from this study towards understanding generic perceptions from more evenly distributed groups of people. Also, the results associated to WTP for SAV and $A B$ should be treated carefully give that the normality assumptions of the WTP models are not fully satisfactory.

Further investigation can be done to find the reasons to explain why increase in knowledge about automated 
driving technology contributes to lesser WTP for AV services. Besides, since this study was carried out when respondents' experiences with transport service operated by AV are still low, further longitudinal studies can be performed to identify whether temporal changes in perceptions and WTP for the AV services correspond to increase in experiences of taking AV rides. Also, willingness to use the three types of AV services can be further analysed in a more detailed manner.

\section{Appendix 1}

Table 4 is the pattern matrix of the service quality attribute perceptions included as the indicators for the latent variables in structural equation model. The table contains the unrotated factor loadings, which indicate the correlations between the variables and the speculated factors. The values can range from -1 to +1 . Correlations more than 0.3 are significant. Factor 1 was assigned as TravelFare, Factor 2 as TravelTime, Factor 3 as Safety, Factor 4 as Cybersecurity and Factor 5 as RideComfort. They are the service quality attributes perceptions included in the model. Table 5 shows the correlations of the identified factor. The correlations between the factors are low except Factor 3 - Safety and Factor 5 RideComfort have slightly high correlation (0.505).

Table 4 Pattern matrix of the service quality attribute perceptions included as the indicators for the latent variables in structural equation model

\begin{tabular}{|c|c|c|c|c|c|}
\hline \multicolumn{6}{|l|}{ Pattern Matrix ${ }^{a}$} \\
\hline & \multicolumn{5}{|c|}{ Factor } \\
\hline & 1 & 2 & 3 & 4 & 5 \\
\hline SafetyWithoutSteward & & & 0.579 & & \\
\hline Safety_Pedestrian & & & 0.758 & & \\
\hline Safety_OnRoad & & & 0.836 & & \\
\hline Cybersecurity_Hacked & & & & 1.004 & \\
\hline Cybersecurity_GPS & & & & 0.663 & \\
\hline RideComfort_Tech & & & & & 0.865 \\
\hline RideComfort_Facilities & & & & & 0.726 \\
\hline OverallRideComfort & & & & & 0.411 \\
\hline Time_RegularPublicBus & & 0.522 & & & \\
\hline Time_Metro & & 0.903 & & & \\
\hline Time_Train & & 0.802 & & & \\
\hline Time_Car & & 0.601 & & & \\
\hline Fare_RegularPublicBus & 0.803 & & & & \\
\hline Fare_Metro & 0.904 & & & & \\
\hline Fare_Train & 0.854 & & & & \\
\hline
\end{tabular}

Extraction Method: Maximum Likelihood Rotation Method: Promax with Kaiser Normalization

${ }^{\text {a }}$ Rotation converged in 5 iterations
Table 5 Factor correlation matrix of the extracted factors from the indicators of the latent variables in structural equation model

\begin{tabular}{llllll}
\hline \multicolumn{7}{l}{ Factor Correlation Matrix } \\
\hline Factor & 1 & 2 & 3 & 4 & 5 \\
\hline 1 & 1.000 & 0.297 & 0.285 & 0.092 & 0.254 \\
2 & 0.297 & 1.000 & 0.317 & 0.089 & 0.366 \\
3 & 0.285 & 0.317 & 1.000 & 0.020 & 0.505 \\
4 & 0.092 & 0.089 & 0.020 & 1.000 & 0.124 \\
5 & 0.254 & 0.366 & 0.505 & 0.124 & 1.000 \\
\hline
\end{tabular}

Extraction Method: Maximum Likelihood

Rotation Method: Promax with Kaiser Normalization

\section{Appendix 2}

\subsection{Assumptions checking for multiple linear regression}

Structural Equation Model applies multiple linear regression analyses. For valid multiple linear regression, three assumptions are checked. Firstly, the residuals of the regression have to be normally distributed. This assumption can be checked by looking at the histograms and normal p-p plot of the residuals of the regression. The bold black line in the histograms and normal p-p plot indicates the line when there is normality. The histograms and normal p-p plots of the residuals of the regression as shown in Figs. 7-12 show that the distributions are not fully following normal distribution. Model A (explanatory variables against WTP for PAV) has satisfactory normality while Models B and C have larger discrepancies from the normality line. This poses a limitation to the results and the results presented for SAV and AB service should thus be treated carefully.

Secondly, there must be no or little multicollinearity in the data. Multicollinearity was tested by assessing the matrix of Pearson's Bivariate Correlation among all independent variables. The correlation coefficients need to be smaller than 0.8 to indicate insignificant multicollinearity. All the correlation coefficients among the independent variables are less than 0.8 in the correlation matrix generated using SPSS statistical tool. This implies insignificant multicollinearity in the data.

Lastly, the data should be homoscedastic. This can be checked by assessing the scatter plots of residuals versus predicted values of the models as shown in Figs. 13, 14 and 15. There is no clear pattern of specific shape, but the residuals are equal across the regression line (the line which cuts through $\mathrm{X}$ and $\mathrm{Y}$ axes) which indicates the data are homoscedastic. The data can be considered sufficiently homoscedastic because there is no clear pattern of specific shape in the distribution and the data are fairly equal across the regression line. 


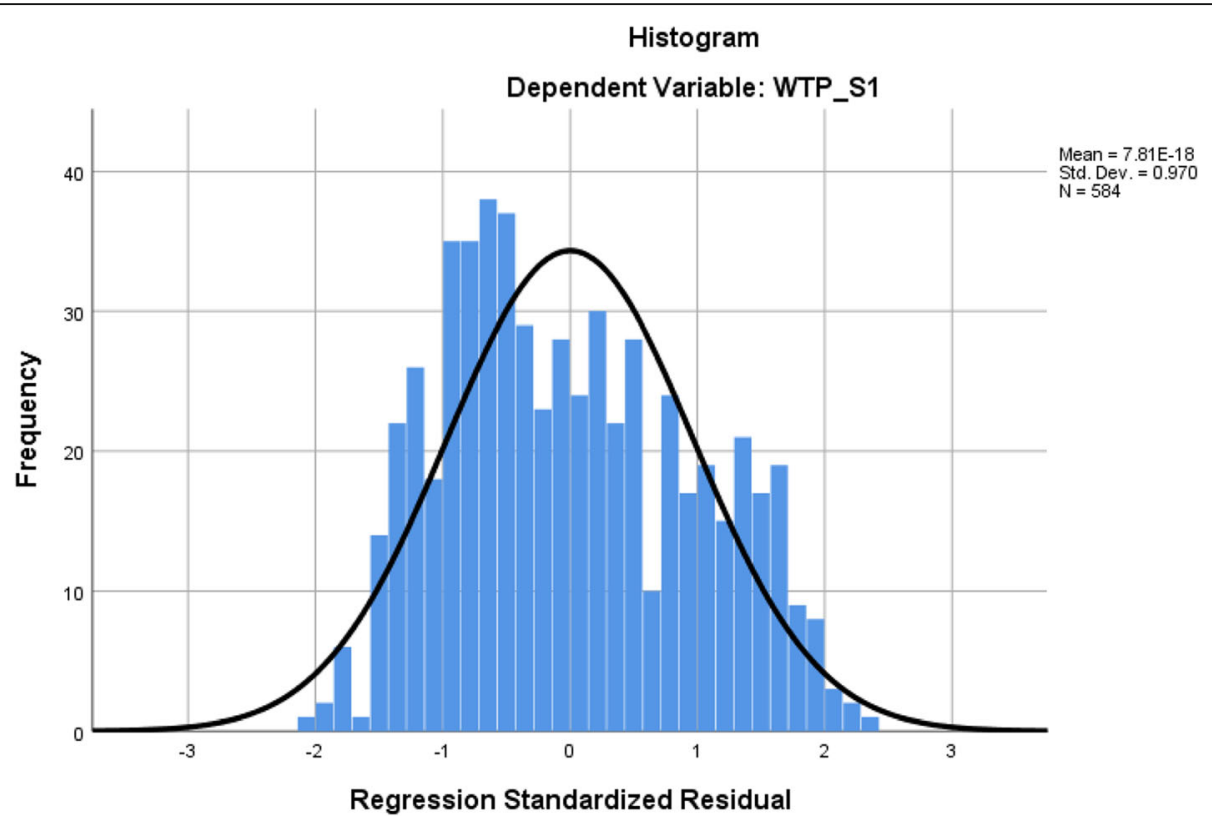

Fig. 7 Histogram of the residuals of regression of Model A (explanatory variables against WTP for PAV)

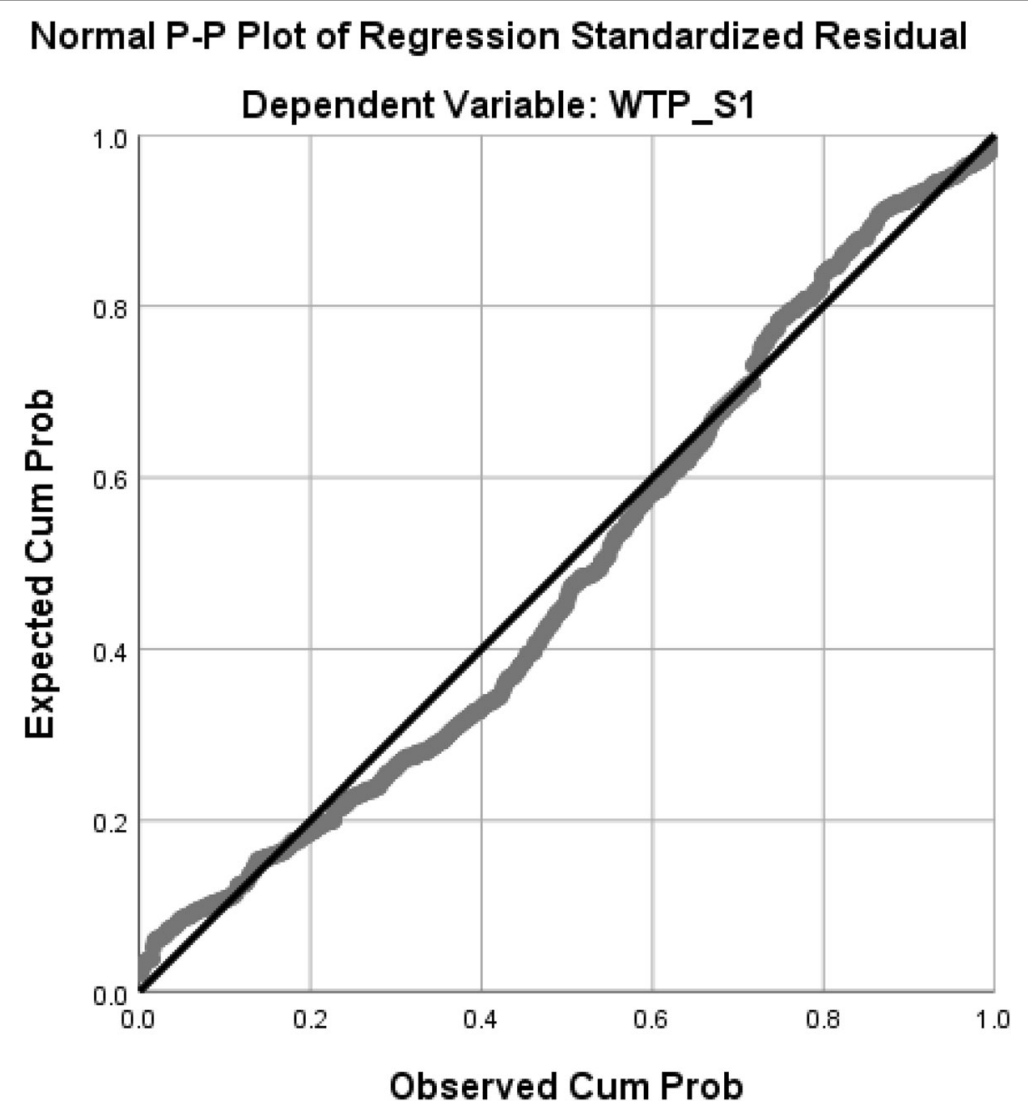

Fig. 8 Normal P-P Plot of the residuals of regression of Model A (explanatory variables against WTP for PAV) 


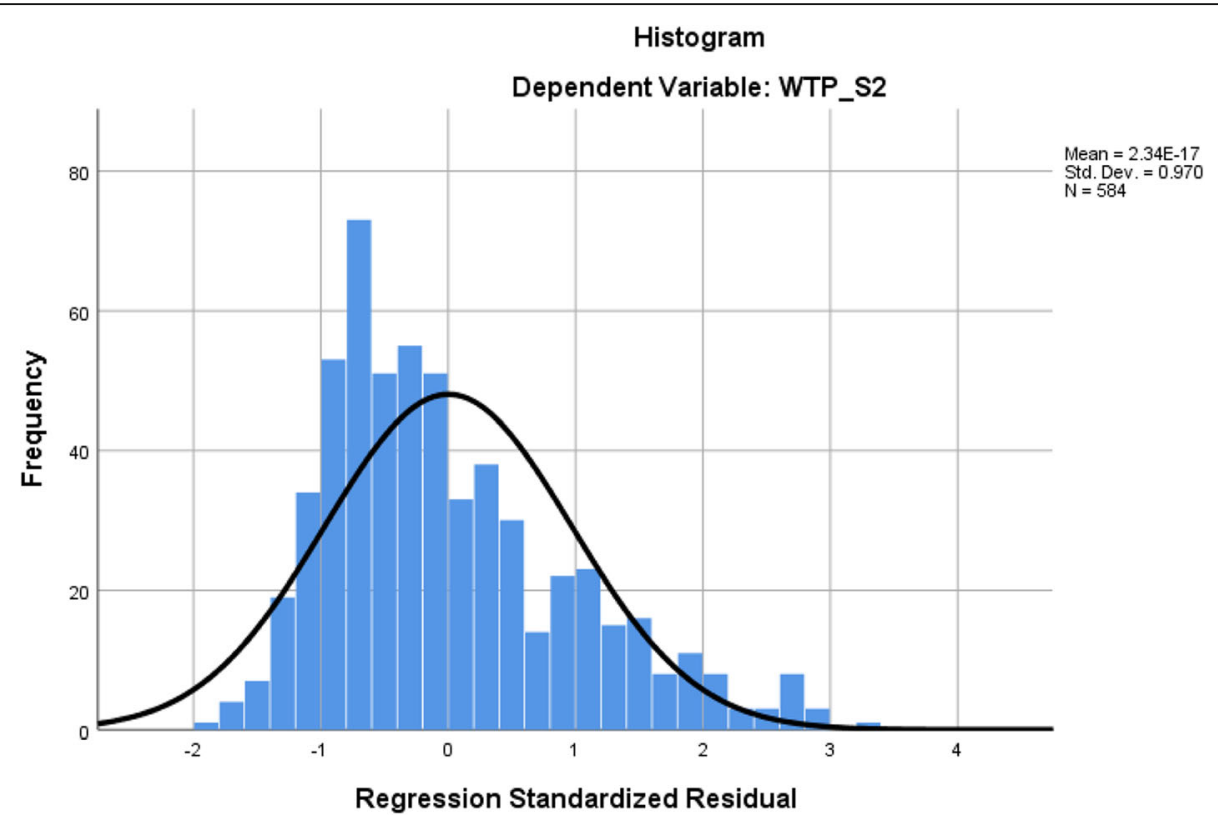

Fig. 9 Histogram of the residuals of regression of Model B (explanatory variables against WTP for SAV)

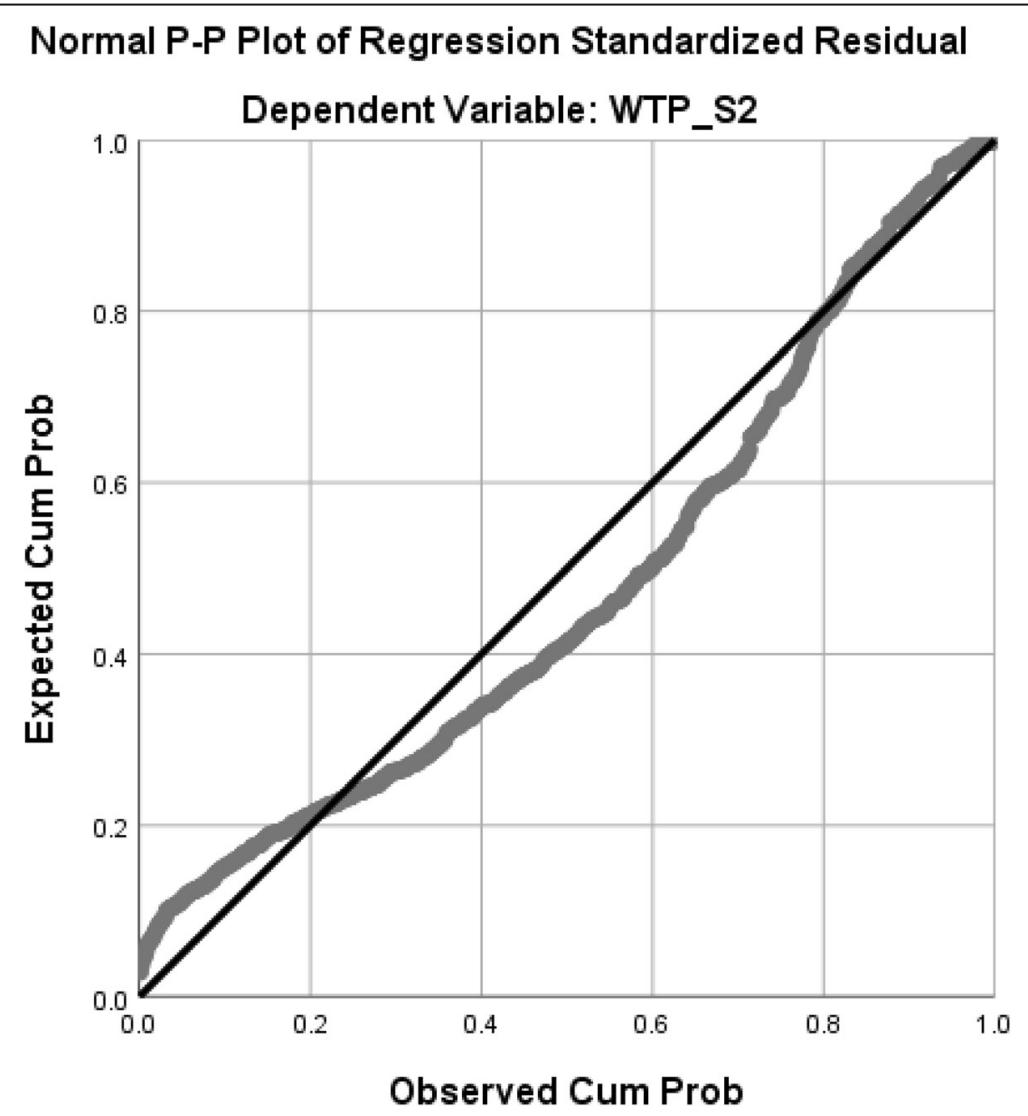

Fig. 10 Normal P-P Plot of the residuals of regression of Model B (explanatory variables against WTP for SAV) 


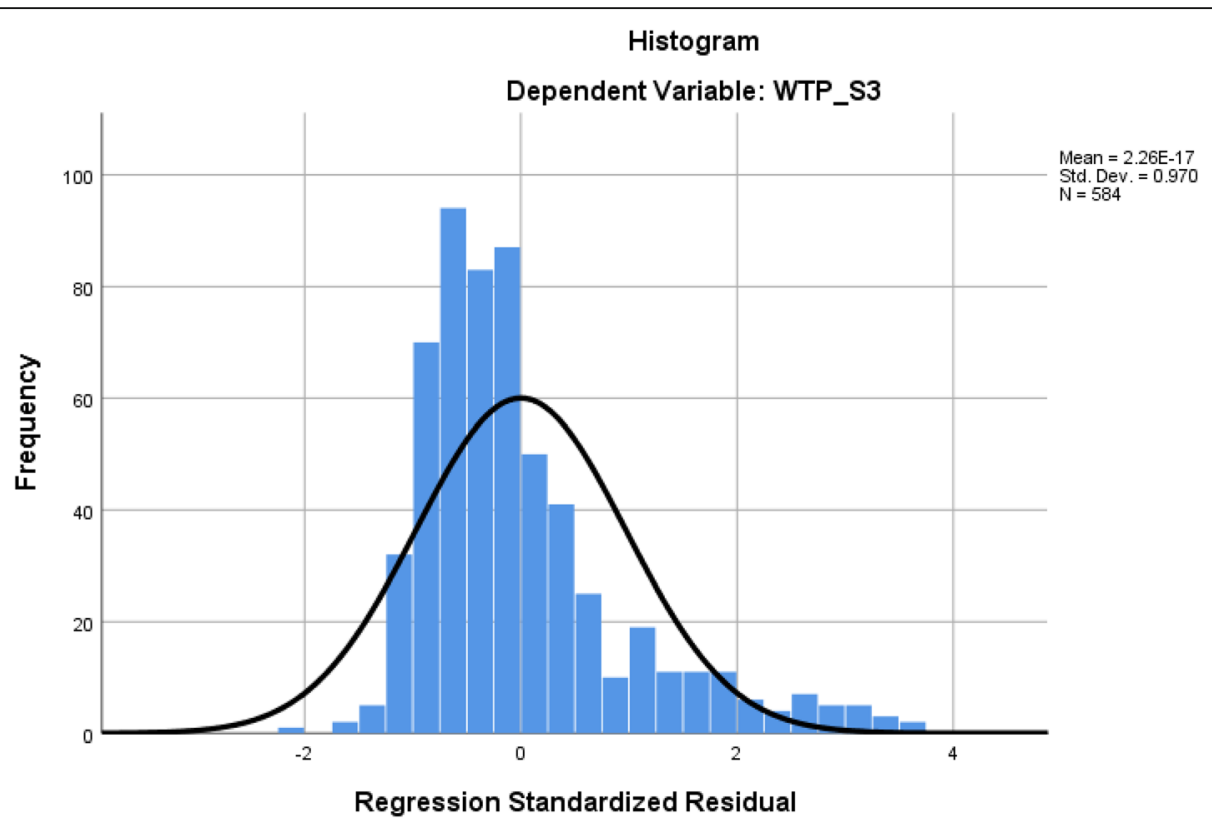

Fig. 11 Histogram of the residuals of regression of Model C (explanatory variables against WTP for AB)

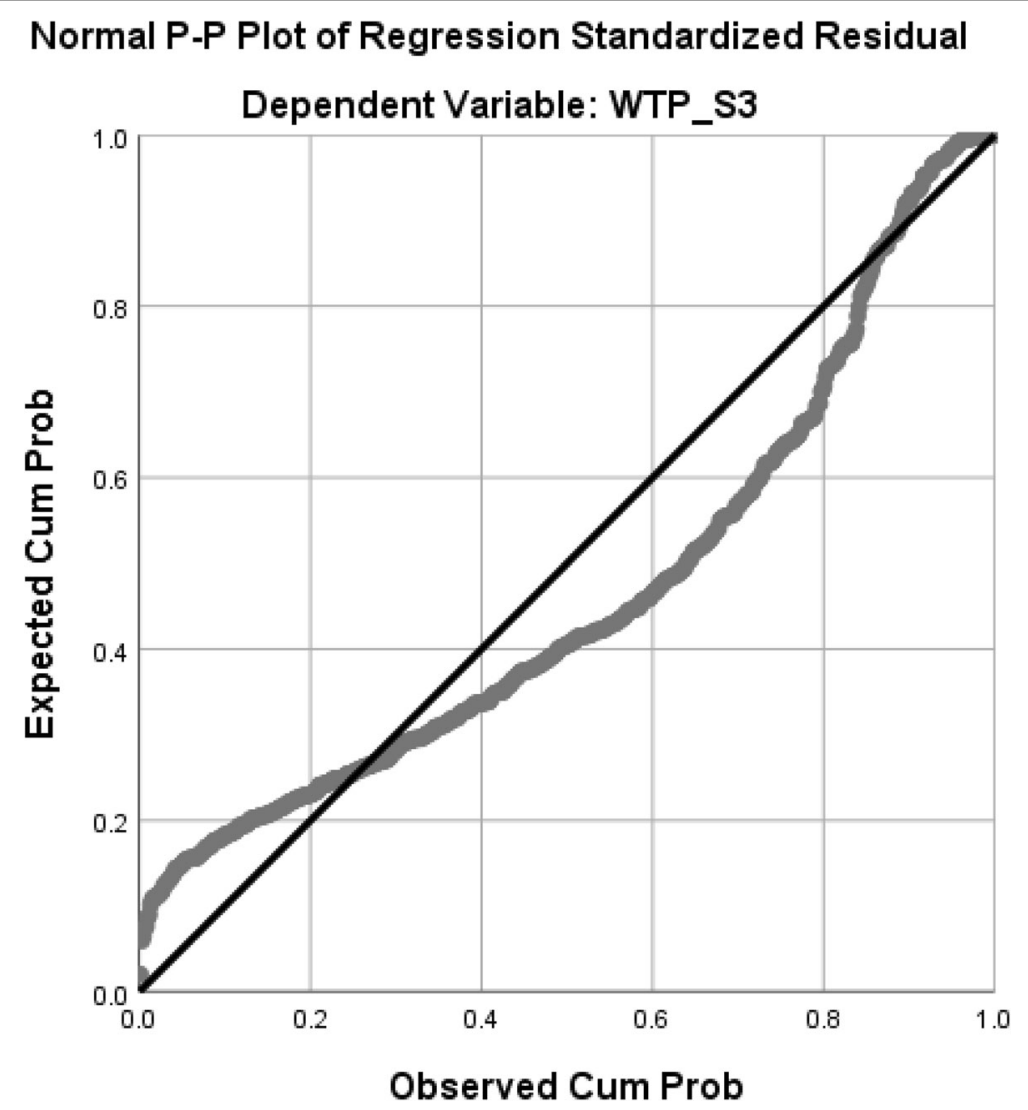

Fig. 12 Normal P-P Plot of the residuals of regression of Model C (explanatory variables against WTP for AB) 

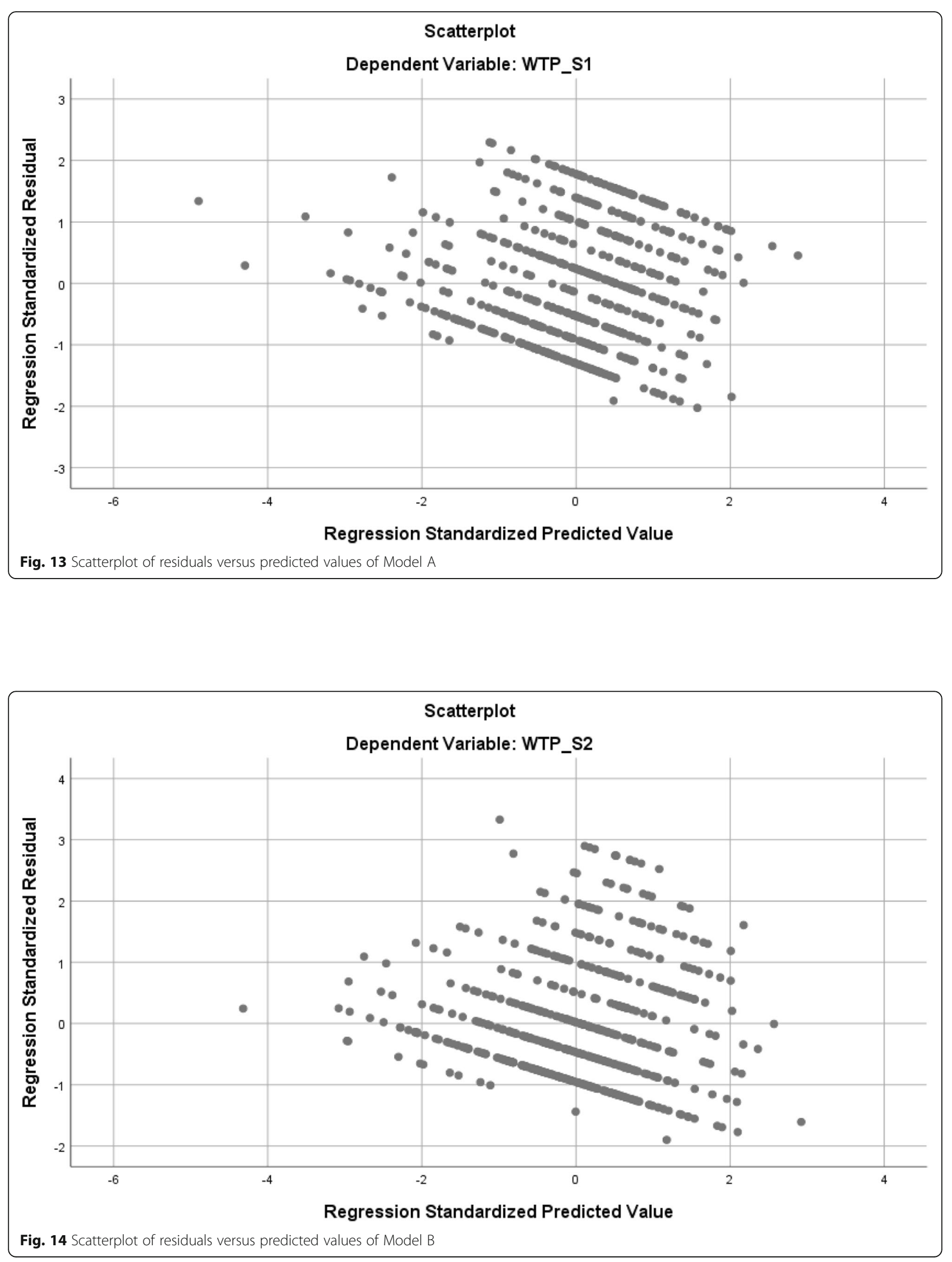


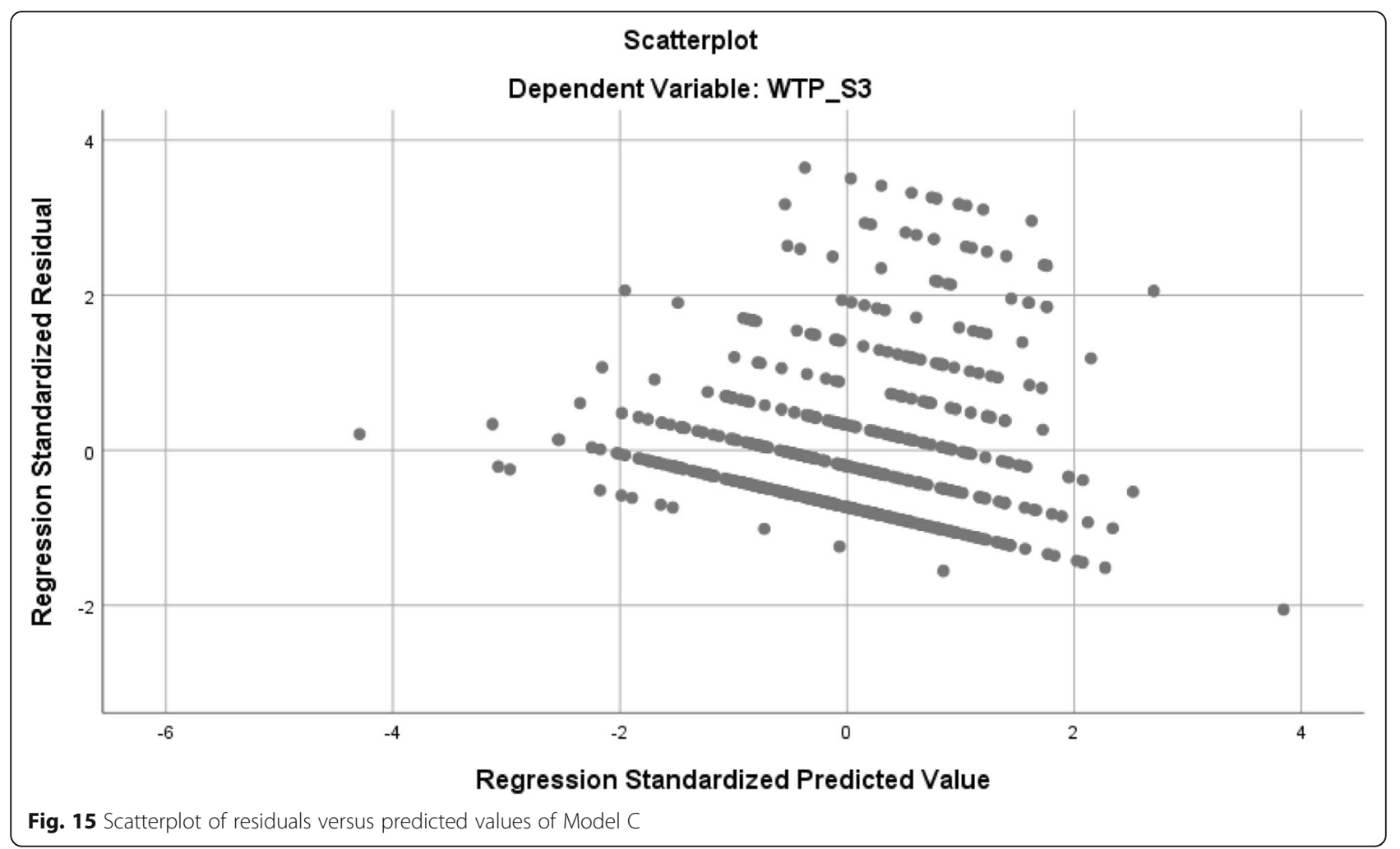

\section{Abbreviations}

AB: Automated bus; AV: Automated vehicle; CAV: Connected automated vehicle; GFI: Goodness of Fit; PAV: Personalised automated vehicle; RMSEA: Root Mean Square Error of Approximation; SAV: Shared automated vehicle; SRMR: Standardised Root Mean Square Residual; WTP: Willingness-topay; WTU: Willingness-to-use

\section{Acknowledgments}

This study is part of first author's research programme while reading a joint NTU-KTH PhD degree, with scholarship funded by Nanyang Technological University, Singapore. The case study is based on a project funded by the Vinnova strategic innovation program Drive Sweden (grant number 201605313) which ended in October 2018. It had been coordinated by ITRL Integrated Transport Research Lab at KTH Royal Institute of Technology, and the research activities were conducted by KTH researchers in collaboration with Nobina AB.

\section{Authors' contributions}

PeiNen Esther Chee: Conceptualization, Methodology, Formal analysis, Investigation, Writing - Original Draft; Yusak O. Susilo: Conceptualization, Writing - Review \& Editing, Supervision, Funding acquisition; Anna Pernestål: Writing - Review \& Editing, Funding acquisition; Yiik Diew Wong: Writing - Review \& Editing. The author(s) read and approved the final manuscript.

\section{Funding}

Open access funding provided by Royal Institute of Technology.

\section{Competing interests}

The authors declare that they have no competing interests.

\section{Author details}

${ }^{1}$ School of Civil and Environmental Engineering, Nanyang Technological University, 50 Nanyang Avenue, Singapore 639798, Singapore. ${ }^{2}$ School of Architecture and Built Environment, Integrated Transport Research Lab, KTH Royal Institute of Technology, SE-100 44 Stockholm, Sweden. ${ }^{3}$ Digitalisation and Automation in Transport and Mobility System, University of Natural
Resources and Life Sciences, Peter Jordan St 82, 1190 Vienna, Austria. ${ }^{4}$ Integrated Transport Research Lab, KTH Royal Institute of Technology, Drottning Kristinas väg 40, SE-100 44 Stockholm, Sweden.

Received: 6 July 2019 Accepted: 19 February 2020

Published online: 07 April 2020

\section{References}

1. Abenoza, R. F., Cats, O., \& Susilo, Y. O. (2017). Travel satisfaction with public transport: Determinants, user classes, regional disparities and their evolution. Transportation Research Part A: Policy and Practice, 95, 64-84. https///doi.org/10.1016/1.tra.2016.11.011.

2. Asgari, H., \& Jin, X. (2019). Incorporating attitudinal factors to examine adoption of and willingness to pay for autonomous vehicles. Transportation Research Record. https://doi.org/10.1177/0361198119839987.

3. Balderiahn, I. (2003). Handbuch. Preispolitik: Strategien - Planung Organisation - Umsetzung (pp. 387-404). Wiesbaden: Springer Gabler.

4. Bansal, P., \& Daziano, R. A. (2018). Influence of choice experiment designs on eliciting preferences for autonomous vehicles. Transportation Research Procedia, 32, 474-481. https://doi.org/10.1016/j.trpro.2018.10.044.

5. Bansal, P., \& Kockelman, K. M. (2017). Forecasting Americans' long-term adoption of connected and autonomous vehicle technologies. Transportation Research Part A: Policy and Practice, 95, 49-63. https://doi.org/ 10.1016/j.tra.2016.10.013.

6. Bansal, P. \& Kockelman, K. M. (2018). Are we ready to embrace connected and self-driving vehicles? A case study of texans. Transportation, 45, 641675. https://doi.org/10.1007/s11116-016-9745-Z.

7. Bansal, P., Kockelman, K. M., \& Singh, A. (2016). Assessing public opinions of and interest in new vehicle technologies: An Austin perspective. Transportation Research Part C: Emerging Technologies, 67, 1-14. https://doi. org/10.1016/j.trc.2016.01.019.

8. Ben-Akiva, M., Walker, J., Bernardino, A. T., Gopinath, D. A., Morikawa, T., \& Polydoropoulou, A. (2002). Integration of choice and latent variable models. In Perpetual motion: Travel behaviour research opportunities and application challenges (pp. 431-470).

9. Breidert, C., Hahsler, M., \& Reutterer, T. (2015). A review of methods for measuring willingness-to-pay. Innovative Marketing, 1. 
10. Daziano, R. A., Sarrias, M., \& Leard, B. (2017). Are consumers willing to pay to let cars drive for them? Analyzing response to autonomous vehicles. Transportation Research Part C: Emerging Technologies, 78, 150-164. https:// doi.org/10.1016/j.trc.2017.03.003.

11. Eden, G., Nanchen, B., Ramseyer, R., \& Evéquoz, F. (2017). Expectation and experience: Passenger acceptance of autonomous public transportation vehicles. In Lecture notes in computer science (including subseries lecture notes in artificial intelligence and lecture notes in bioinformatics) (Vol. 10516 LNCS, pp. 360-363). https://doi.org/10.1007/ 978-3-319-68059-0_30

12. Fraedrich, E., Heinrichs, D., Bahamonde-Birke, F. J., \& Cyganski, R. (2019). Autonomous driving, the built environment and policy implications. Transportation Research Part A: Policy and Practice, 122, 162-172. https://doi. org/10.1016/j.tra.2018.02.018.

13. Google Maps. (2018). Image of route where EZ10 operated during the trial operation period, retrieved from Googlep Maps.

14. Jiang, Y., Zhang, J., Wang, Y., \& Wang, W. (2019). Capturing ownership behavior of autonomous vehicles in Japan based on a stated preference survey and a mixed logit model with repeated choices. International Journal of Sustainable Transportation, 13(10), 788-801. https://doi.org/10.1080/ 15568318.2018 .1517841$.

15. Kotler, P., Armstrong, G., Wong, V., \& Saunders, J. (2008). Principle of marketing (5th ed.). Rotolito: Pearson Education Limited.

16. Krueger, R., Rashidi, T. H., \& Rose, J. M. (2016). Preferences for shared autonomous vehicles. Transportation Research Part C: Emerging Technologies, 69, 343-355. https://doi.org/10.1016/j.trc.2016.06.015.

17. Kyriakidis, M., Happee, R., \& De Winter, J. C. F. (2015). Public opinion on automated driving: Results of an international questionnaire among 5000 respondents. Transportation Research Part F: Traffic Psychology and Behaviour, 32, 127-140. https://doi.org/10.1016/j.trf. 2015.04.014.

18. Ligas, M., \& Chaudhuri, A. (2012). The moderating roles of shopper experience and store type on the relationship between perceived merchandise value and willingness to pay a higher price. Journal of Retailing and Consumer Services, 19(2), 249-258. https://doi.org/10.1016/J. JRETCONSER.2012.01.006.

19. Liu, P., Yang, R., \& Xu, Z. (2019). Public acceptance of fully automated driving: Effects of social trust and risk/benefit perceptions. Risk Analysis, 39(2), 326-341. https://doi.org/10.1111/risa.13143.

20. McDonald, M., Site, P. D., Stam, D., \& Salucci, M. V. (2018). Evaluation of automated road transport systems in cities. In Implementing automated road transport systems in urban settings (pp. 81-207). Elsevier. https://doi.org/10. 1016/b978-0-12-812993-7.00003-6.

21. Netemeyer, R. G., Krishnan, B., Pullig, C., Wang, G., Yagci, M., Dean, D., et al. (2004). Developing and validating measures of facets of customer-based brand equity. Journal of Business Research, 57(2), 209-224. https://doi.org/10. 1016/S0148-2963(01)00303-4.

22. Pakusch, C., Stevens, G., Boden, A., \& Bossauer, P. (2018). Unintended effects of autonomous driving: A study on mobility preferences in the future. Sustainability, 10(7), 2404. https://doi.org/10.3390/su10072404.

23. Piao, J., McDonald, M., Hounsell, N., Graindorge, M., Graindorge, T., \& Malhene, N. (2016). Public views towards implementation of automated vehicles in urban areas. Transportation Research Procedia, 14(0), 2168-2177. https://doi.org/10.1016/j.trpro.2016.05.232.

24. Salonen, A. O. (2018). Passenger's subjective traffic safety, in-vehicle security and emergency management in the driverless shuttle bus in Finland. Transport Policy, 61(October 2017), 106-110. https://doi.org/10.1016/j.tranpol. 2017.10.011

25. Scheltes, A., \& de Almeida Correia, G. H. (2017). Exploring the use of automated vehicles as last mile connection of train trips through an agentbased simulation model: An application to Delft, Netherlands. International Journal of Transportation Science and Technology, 6(1), 28-41. https://doi. org/10.1016/j.ijtst.2017.05.004

26. Schoettle, B., \& Sivak, M. (2014). Public opinion about self-driving vehicles in China, India, Japan, the U.S., the U.K. and Australia, (UMTRI-2014-30 (October)) (pp. 1-85) https://doi.org/UMTRI-2014-30.

27. Shin, J., Bhat, C. R., You, D., Garikapati, V. M., \& Pendyala, R. M. (2015). Consumer preferences and willingness to pay for advanced vehicle technology options and fuel types. Transportation Research Part C: Emerging Technologies, 60, 511-524. https://doi.org/10.1016/j.trc.2015.10.003.
28. Talebian, A., \& Mishra, S. (2018). Predicting the adoption of connected autonomous vehicles: A new approach based on the theory of diffusion of innovations. Transportation Research Part C: Emerging Technologies, 95, 363380. https://doi.org/10.1016/j.trc.2018.06.005

29. Vinson, D. E., Scott, J. E., \& Lamont, L. M. (1977). The role of personal values in marketing and consumer behavior. The Journal of Marketing, 41(2), 44-50. https://doi.org/10.2307/1250633.

\section{Publisher's Note}

Springer Nature remains neutral with regard to jurisdictional claims in published maps and institutional affiliations.

\section{Submit your manuscript to a SpringerOpen ${ }^{\circ}$ journal and benefit from:}

- Convenient online submission

- Rigorous peer review

- Open access: articles freely available online

High visibility within the field

- Retaining the copyright to your article

Submit your next manuscript at $\boldsymbol{\nabla}$ springeropen.com 